\title{
Health Risk Assessment on Pesticide Residues in Drinking Water in Shenzhen
}

\author{
Guohong Liu, Ziqian Xu, Xinyun Xu, Zhaoqiong Peng, Jin Li, Guangwen Huang, Wei Wang \\ Shenzhen Center for Disease Control and Prevention, Shenzhen, China \\ Email: liugh6610@163.com
}

How to cite this paper: Liu, G.H., Xu, Z.Q., Xu, X.Y., Peng, Z.Q., Li, J., Huang, G.W. and Wang, W. (2018) Health Risk Assessment on Pesticide Residues in Drinking Water in Shenzhen. Occupational Diseases and Environmental Medicine, 6, 119-129.

https://doi.org/10.4236/odem.2018.64010

Received: August 15, 2018

Accepted: October 7, 2018

Published: October 10, 2018

Copyright () 2018 by authors and Scientific Research Publishing Inc. This work is licensed under the Creative Commons Attribution International License (CC BY 4.0).

http://creativecommons.org/licenses/by/4.0/

\begin{abstract}
Objectives: To conduct health risk assessment of drinking water pesticide residues and its annual trend analysis in Shenzhen City. Methods: The samples of product water, pipe water and secondary supply water from 2011 to 2013 were collected and analyzed. The evaluation models of health risk assessments for children and adults on the 12 non-carcinogenic materials (namely heptachlor, pentachlorophenol, hexachlorocyclohexane, hexachlorobenzene, DDT, malathion, glyphosate, dimethoate, bentazone, atrazine, chlorothalonil, furadan) were recommended by the U.S. Environmental Protection Agency (US EPA). Results: The results showed that the maximums of the measured indicators in the above were controlled in accordance with the National Health Standards (GB5749-2006) published by Ministry of Health in China. The adults and children's health indices (HIs) of the 12 non-carcinogenic materials were greater than $1(2.323-6.312)$. Dimethoate residue in factory and peripheral water was the largest risks of harm among the non-carcinogenic pollutants measured. And its $\mathrm{HI}_{\mathrm{i}}$ (Its $\mathrm{Hl}_{\mathrm{i}}$ ) was also greater than 1 (1.995 5.094) and followed by hexachlorobenzene and heptachlor. Annual rising trend on health risk of the 12 pesticide residues indicated that their $\mathrm{HI}_{\mathrm{T}}$ on adults was 2323. $18 \times 10^{-3}$ in 2011, 2340. $18 \times 10^{-3}$ in 2012 and $2431.97 \times 10^{-3}$ in 2013 , and $\mathrm{HI}_{\mathrm{T}}$ on children was $2965.07 \times 10^{-3}$ in $2011,2986.77 \times 10^{-3}$ in 2012 and $3103.93 \times 10^{-3}$ in 2013 , respectively. This study also suggested that the average risk of peripheral water samples $\left(\mathrm{HI}_{\mathrm{T}}\right.$ was equal to $2619.64 \times$ $\left.10^{-3}\right)$ was greater than the factory samples' $\left(\mathrm{HI}_{\mathrm{T}}\right.$ was the same as $2366.92 \times$ $\left.10^{-3}\right)$, and the children's health risk was greater than the adults'. Conclusions: Health risks of drinking water pesticide residues in Shenzhen have exceeded the threshold values. The dimethoate was the main hazard and had been rising annually, and the children's health risk was greater than the adults'.
\end{abstract}

\section{Keywords}

Drinking Water, Pesticide Residues, Health Risk Assessment, Annual Trend 
Analysis

\section{Introduction}

The term "pesticide" is a general term that includes many compounds used for a wide variety of purposes to control a range of living organisms. It includes animal and bird repellents, food storage protectants, insecticides and acaricides, mould-killing substances, antifouling products, plant growth regulators, compounds used to prevent the growth of lichen and mosses etconbuildings, rodenticides, soil sterilants, weed killers and wood preservatives and so on [1] [2]. In the recent years, the pesticide industry in China has developed very rapidly, and the pesticide production has been the second largest producer in the world for many years, but overtook the United States and became the largest pesticide producer by breaking through the million tons in the world in 2005 [2] [3]. Some parts of the environmental pesticide residues couldn't be removed absolutely by the modern drinking water treatment technologies, such as precipitation, filtration and disinfection, which remained in the surface and groundwater after the atmosphere-water-soil-biosphere circulation [4] [5] [6] [7]. Organochlorine (OC) pesticides are the one reason of hepatocirrhosis swelling, which could accumulate in human body fat and induce the liver enzymes. Organophosphate (OP) pesticides are the neurotoxic substance, which could cause neurological dysfunction, tremor, delirium, speech disorders, etc. [5] [6]. Just as the following report, concentrations of the 12 kinds of heptachlor chemicals in drinking water have been measured and their health risk assessments have been analyzed from 2011 to 2013 in this study.

\section{Materials and Methods}

\subsection{Experimental}

Drinking water samples were collected in Shenzhen from January 2011 to December 2013, with a total of 84 factory samples, 11 peripheral samples and 1 secondary supplement samples to analyze their pesticide residues (see Figure 1). Detection indexes for these samples included heptachlor, pentachlorophenol, hexachlorocyclohexane, hexachlorobenzene, DDT, malathion, glyphosate, dimethoate, bentazone,Atrazine, chlorothalonil, carbofuran, etc. The Shenzhen Municipal Water Affairs Bureau is responsible for water quality detection of secondary supplement according to the duties of the functional departments of the Shenzhen Municipal Government. Collection, storage and testing of all water samples were in accordance with the Inspection methods of drinking water (GB 5750-2006) [8] for evaluation.

Heptachlor, hexachlorocyclohexane, hexachlorobenzene, DDT and chlorothalonil in drinking water were detected by GC2010 Gas Chromatograph which was made by Shimadzu Corporation in Japan. Pentachlorophenol by GC-17A 


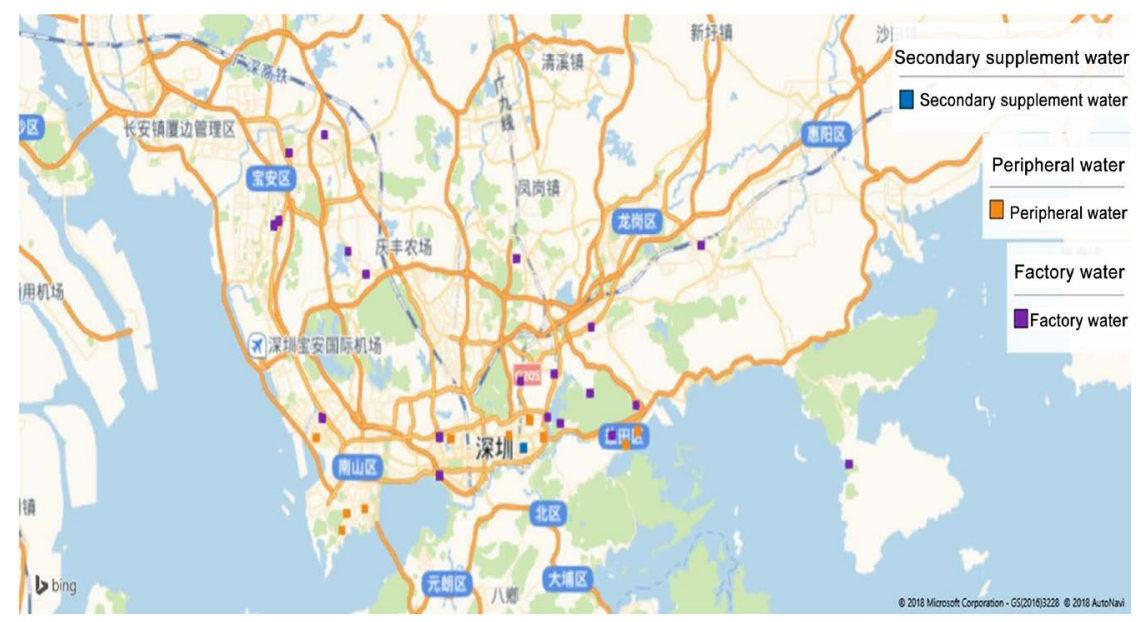

Figure 1. Sampling sites.

Gas Chromatograph of Shimadzu Corporation in Japan. Malathion and LeA by Agilent 7890 Gas Chromatograph of USA. Glyphosate, extinction Grass pine and atrazine by QTRAP 5500 liquid chromatography tandem mass spectrometry Instrument of American ABI company. Carbofuran by Agilent 1100 liquid color Spectrometer of USA. The test results were in accordance with the Standards for Drinking Water Hygiene (GB 5749-2006) for evaluation.

In view of data quality assurance, each sample was analyzed in triplicate and after every 10 samples two standards; one blank and another of $2.5 \mu \mathrm{g} / \mathrm{L}$ of respective metal were analyzed on atomic absorption. The reproducibility was found to be at 95 percent of confidence level, the relative standard deviations (RSD) were all less than 15 percent, conforming to the requirements of the US EPA which RSD is less than 30 percent [8]. Therefore, the average value of each water sample was used for further interpretation.

\subsection{Pesticide Residues Health Risk Assessment}

Pesticide residues health risk assessment was used to evaluate risks of heptachlor, pentachlorophenol, hexachlorocyclohexane, hexachlorobenzene, DDT, malathion, glyphosate, dimethoate, bentazone, Atrazine, chlorothalonil, carbofuran. Health risk index (HI) means average personal annual health risk values due to exposure to individual non-genetic toxicant. The calculation method is shown in formula (1) to (3) [4] [5] [6]:

$$
\begin{gathered}
\mathrm{HIT}=\sum \mathrm{HIi} \\
\mathrm{HIi}=(\mathrm{CDIi} / \mathrm{RfDi}) \\
\mathrm{CDIi}=(\mathrm{Ci} \times \mathrm{IR} \times \mathrm{EF} \times \mathrm{ED}) /(\mathrm{BW} \times \mathrm{AT})
\end{gathered}
$$

HIT-average personal health risk of total non-genetic toxicants by drinking, annual; $\mathrm{HI}$-average personal health risk of individual non-genetic toxicant by drinking, annual; CDIi-chronic daily exposure dose through drinking, $\mathrm{mg} /(\mathrm{kg} \cdot \mathrm{d}) ; \mathrm{RfDi}-$ reference dose of individual non-genetic toxicant by drinking, $\mathrm{mg} /(\mathrm{kg} \cdot \mathrm{d}) ; \mathrm{Ci}-$ concentration of individual measured substance in water, $\mathrm{mg} / \mathrm{L}$; 
IR-intake rate of water, adult 2.2 L/d, children 1.0 L/d [9]; EF-exposure frequency $(\mathrm{d} / \mathrm{y}) ; \mathrm{ED}$-exposure duration (y); BW-body weight (kg) [10]; AT-average exposure day $(\mathrm{d})$.

There are no basic data on exposure parameters in China at present, so we generally introduced the RfDi, from USEPA to conduct risk assessment (see Table 1) [11].

\subsection{Evaluation Standard}

Testing pesticide residues of water samples were in accordance with the Inspection methods of drinking water (GB 5750-2006) [8] for evaluation. HIi > 1 indicated a potential of the pollutant for an adverse effect on human health or the necessity for further study. HIi $<1$ indicated a relative safety for human health.

\subsection{Data Analysis}

Data entry for water quality monitoring database were performed by Excel 2003. The all data were analyzed descriptive statistically by software program (SPSS 13.0 for windows). After the normality test, the water quality monitoring data was non-normally distributed, so the range and median were used. There was statistical significance if $\mathrm{P}$ value was below to 0.05 .

\section{Results}

1) Determination quality inspection indicators on pesticide residues in drinking water

Testing the pesticide residues of water samples, the minimum detection limit and the recovery rate were in accordance with the Inspection methods of drinking water (GB 5750-2006) [8] for evaluation (see Table 2).

Table 1. Noncarcinogenic reference dose on pesticides in drinking water in US.

\begin{tabular}{ccc}
\hline Pesticide types & Pesticides & RfD $[\mathrm{mg} /(\mathrm{kg} \cdot \mathbf{d})]$ \\
\hline Organochlorine $(\mathrm{OC})$ & Heptachlor & 0.0001 \\
& Pentachlorophenol & 0.0050 \\
& Hexachlorocyclohexane & 0.0030 \\
& Hexachlorobenzene & 0.0008 \\
Organophosphate (OP) & DDT & 0.0200 \\
& Malathion & 0.0200 \\
Herbicide & Glyphosate & 0.1000 \\
& Dimethoate & 0.0002 \\
Fungicide & Bentazone & 0.0300 \\
Carbamate & Atrazine & 0.0350 \\
& Chlorothalonil & 0.0150 \\
& Carbofuran & 0.0010
\end{tabular}


Table 2. Determination parameters on pesticide residues in drinking water.

\begin{tabular}{ccc}
\hline Pesticide/(mg/L) & $\begin{array}{c}\text { Minimum detection } \\
\text { limit }(\mathrm{mg} / \mathrm{L})\end{array}$ & Recovery rate/\% \\
\hline Heptachlor & 0.0004 & $83.0-97.0$ \\
Pentachlorophenol & 0.001 & $93.6-98.1$ \\
Hexachlorocyclohexane & 0.005 & $85.8-108.0$ \\
Hexachlorobenzene & 0.00001 & $81.1-91.0$ \\
DDT & 0.001 & $91.3-102.0$ \\
Malathion & 0.01 & $87.1-90.0$ \\
Glyphosate & 0.00015 & $91.8-99.2$ \\
Dimethoate & 0.01 & $85.2-92.0$ \\
Bentazone & 0.0005 & $97.6-100.0$ \\
Atrazine & 0.001 & $89.0-97.0$ \\
Chlorothalonil & 0.001 & $83.0-112.0$ \\
Carbofuran & 0.002 & $81.0-120.0$ \\
\hline
\end{tabular}

2) Concentrations of pesticide residues in product water, pipe water and secondary supply water in Shenzhen from 2011 to 2013

The samples with a total of 84 factory water, 11 peripheral water and $1 \mathrm{sec}-$ ondary supplement water from 2011 to 2013 have been tested, and the maximum value of the samples did not exceed the limit values according to the Standards for Drinking Water Hygiene (GB 5749-2006). The 6 samples of heptachlor (Upper limit is $0.4 \mu \mathrm{g} / \mathrm{L}$ ), 10 samples of hexachlorocyclohexane (Upper limit is $5.0 \mu \mathrm{g} / \mathrm{L}$ ), and 5 samples of DDT (Upper limit is $1.0 \mu \mathrm{g} / \mathrm{L}$ ) approached to the critical values (see Table 3).

3) Health risk assessment and annual trend for children and adults on the 12 pesticides in drinking water from 2011 to 2013 in Shenzhen

The HIi of children and adults on the 12 pesticides in factory water from 2011 to 2013 in Shenzhen were more than $1(2.323-6.312)$, the HIi of dimethoate were the most important and more than 1 (1.995 - 5.094).There was an upward trend year by year on HIi, and the HIi of adults in $2011<$ HIi in $2012<$ HIi in 2013, and the HIi of children in $2011<$ HIi in $2012<$ HIi in 2013. This study also showed that the health risks of children were higher than risks of adults from the pesticides in drinking water (see Table 4, Figure 2, Figure 3).

4) Non-carcinogenic risk assessment on the 12 pesticides in factory water, pipe water and secondary supply water in Shenzhen

We have detected the median and maximum values of concentrations on the 12 pesticides in 84 factory waters, 11 pipe waters and 1 secondary supply water from 2011 to 2013, which were employed to analyze the non-carcinogenic risk assessment from pesticides. No maximum values of concentrations on secondary supply water because of only one sample. The HIT resulted from the median values of concentrations of the 12 pesticides in the pipe water were higher than 
Table 3. Detection on pesticide residue in drinking water from 2011 to 2013 in Shenzhen $\mu \mathrm{g} / \mathrm{L}$.

\begin{tabular}{|c|c|c|c|c|c|c|c|c|c|}
\hline \multirow{2}{*}{ Pesticide } & \multicolumn{3}{|c|}{ Factory water } & \multicolumn{3}{|c|}{ Peripheral water } & \multicolumn{2}{|c|}{$\begin{array}{c}\text { Secondary } \\
\text { supplement water }\end{array}$} & \multirow{2}{*}{$\begin{array}{l}\text { Standard } \\
\text { limit value }\end{array}$} \\
\hline & $\mathrm{n}$ & mean with SD & Range & $\mathrm{n}$ & mean with SD & Range & $\mathbf{n}$ & Median & \\
\hline Heptachlor & 83 & $0.204 \pm 0.186$ & $0.200-0.400$ & 11 & $0.216 \pm 0.168$ & $0.200-0.400$ & 1 & 0.200 & 0.4 \\
\hline Pentachlorophenol & 84 & $0.617 \pm 0.406$ & $0.500-5.000$ & 11 & $0.952 \pm 0.617$ & $0.500-5.000$ & 1 & 5.000 & 9.0 \\
\hline Hexachlorocyclohexane & 84 & $2.122 \pm 1.745$ & $0.200-5.000$ & 11 & $2.514 \pm 1.921$ & $0.200-5.000$ & 1 & 2.500 & 5.0 \\
\hline Hexachlorobenzene & 53 & $0.071 \pm 0.053$ & $0.002-0.500$ & 11 & $0.095 \pm 0.0643$ & $0.005-0.850$ & 1 & 0.005 & 1.0 \\
\hline DDT & 84 & $0.453 \pm 0.319$ & $0.200-1.000$ & 11 & $0.543 \pm 0.368$ & $0.500-1.000$ & 1 & 0.500 & 1.0 \\
\hline Malathion & 84 & $6.128 \pm 4.227$ & $5.000-50.000$ & 11 & $5.451 \pm 3.817$ & $5.000-10.000$ & 1 & 5.000 & 250.0 \\
\hline Glyphosate & 84 & $0.154 \pm 0.106$ & $0.080-0.250$ & 11 & $0.128 \pm 0.104$ & $0.100-0.200$ & 1 & 0.080 & 700.0 \\
\hline Dimethoate & 83 & $5.014 \pm 4.581$ & $0.500-10.000$ & 11 & $5.452 \pm 4.167$ & $5.000-10.000$ & 1 & 5.000 & 80.0 \\
\hline Bentazone & 84 & $0.206 \pm 0.164$ & $0.150-0.500$ & 11 & $0.452 \pm 0.282$ & $0.160-2.500$ & 1 & 0.250 & 300.0 \\
\hline Atrazine & 84 & $0.277 \pm 0.201$ & $0.025-1.000$ & 11 & $0.413 \pm 0.375$ & $0.025-1.000$ & 1 & 0.500 & 2.0 \\
\hline Chlorothalonil & 84 & $0.503 \pm 0.452$ & $0.500-1.000$ & 11 & $0.542 \pm 0.382$ & $0.500-1.000$ & 1 & 0.500 & 10.0 \\
\hline Carbofuran & 84 & $1.011 \pm 0.926$ & $1.000-2.000$ & 11 & $1.089 \pm 0.837$ & $1.000-2.000$ & 1 & 1.000 & 7.0 \\
\hline
\end{tabular}

Table 4. Non-carcinogenic risk assessment for children and adults on the 12 pesticides in drinking water from 2011 to 2013 in Shenzhen $\left(\times 10^{-3}\right)$.

(a)

\begin{tabular}{ccccccc}
\hline \multirow{2}{*}{ Pesticides } & \multicolumn{5}{c}{ The risk of adults } \\
\cline { 2 - 7 } & \multicolumn{2}{c}{2011} & \multicolumn{2}{c}{2012} & \multicolumn{2}{c}{2013} \\
\cline { 2 - 7 } & Median & Maximum & Median & Maximum & Median & Maximum \\
\hline Heptachlor & 159.67 & 239.50 & 159.67 & 159.67 & 239.50 & 319.34 \\
Pentachlorophenol & 9.58 & 79.83 & 12.77 & 15.97 & 9.58 & 79.83 \\
Hexachlorocyclohexane & 42.58 & 133.06 & 66.53 & 66.53 & 66.53 & 133.06 \\
Hexachlorobenzene & 6.79 & 9.98 & 0.20 & 0.20 & 8.08 & 49.90 \\
DDT & 1.60 & 2.00 & 2.00 & 2.00 & 2.04 & 3.99 \\
Malathion & 23.95 & 199.59 & 19.96 & 19.96 & 24.35 & 199.59 \\
Glyphosate & 0.19 & 0.20 & 0.20 & 0.20 & 0.06 & 0.12 \\
Dimethoate & 1995.85 & 3991.71 & 1995.85 & 1995.85 & 1995.85 & 3991.71 \\
Bentazone & 0.43 & 0.45 & 0.45 & 0.45 & 0.69 & 1.33 \\
Atrazine & 0.05 & 0.06 & 0.06 & 0.06 & 1.14 & 2.28 \\
Chlorothalonil & 2.66 & 2.66 & 2.66 & 2.66 & 2.71 & 5.38 \\
Carbofuran & 79.83 & 79.83 & 79.83 & 79.83 & 81.43 & 159.67 \\
Total & 2323.18 & 4738.86 & 2340.18 & 2343.37 & 2431.97 & 4946.18 \\
\hline
\end{tabular}

(b)

\begin{tabular}{ccccccc}
\hline \multirow{2}{*}{ Pesticides } & \multicolumn{5}{c}{ The risk of children } \\
\cline { 2 - 7 } & \multicolumn{2}{c}{2011} & \multicolumn{2}{c}{2012} & \multicolumn{2}{c}{2013} \\
\cline { 2 - 7 } & Median & Maximum & Median & Maximum & Median & Maximum \\
\hline Heptachlor & 203.78 & 305.68 & 203.78 & 203.78 & 305.68 & 407.57 \\
Pentachlorophenol & 12.23 & 101.89 & 16.30 & 20.38 & 12.23 & 101.89 \\
\hline
\end{tabular}




\section{Continued}

\begin{tabular}{ccccccc}
\hline Hexachlorocyclohexane & 54.34 & 169.82 & 84.91 & 84.91 & 84.91 & 169.82 \\
Hexachlorobenzene & 8.66 & 12.74 & 0.25 & 0.25 & 10.32 & 63.68 \\
DDT & 2.04 & 2.55 & 2.55 & 2.55 & 2.60 & 5.09 \\
Malathion & 30.57 & 254.73 & 25.47 & 25.47 & 31.08 & 254.73 \\
Glyphosate & 0.24 & 0.25 & 0.25 & 0.25 & 0.08 & 0.15 \\
Dimethoate & 2547.31 & 5094.61 & 2547.31 & 2547.31 & 2547.31 & 5094.61 \\
Bentazone & 0.54 & 0.58 & 0.58 & 0.58 & 0.88 & 1.70 \\
Atrazine & 0.07 & 0.07 & 0.07 & 0.07 & 1.46 & 2.91 \\
Chlorothalonil & 3.40 & 3.40 & 3.40 & 3.40 & 3.46 & 6.86 \\
Carbofuran & 101.89 & 101.89 & 101.89 & 101.89 & 103.93 & 203.78 \\
Total & 2968.07 & 6048.21 & 2986.77 & 2990.85 & 3103.93 & 6312.81 \\
\hline
\end{tabular}

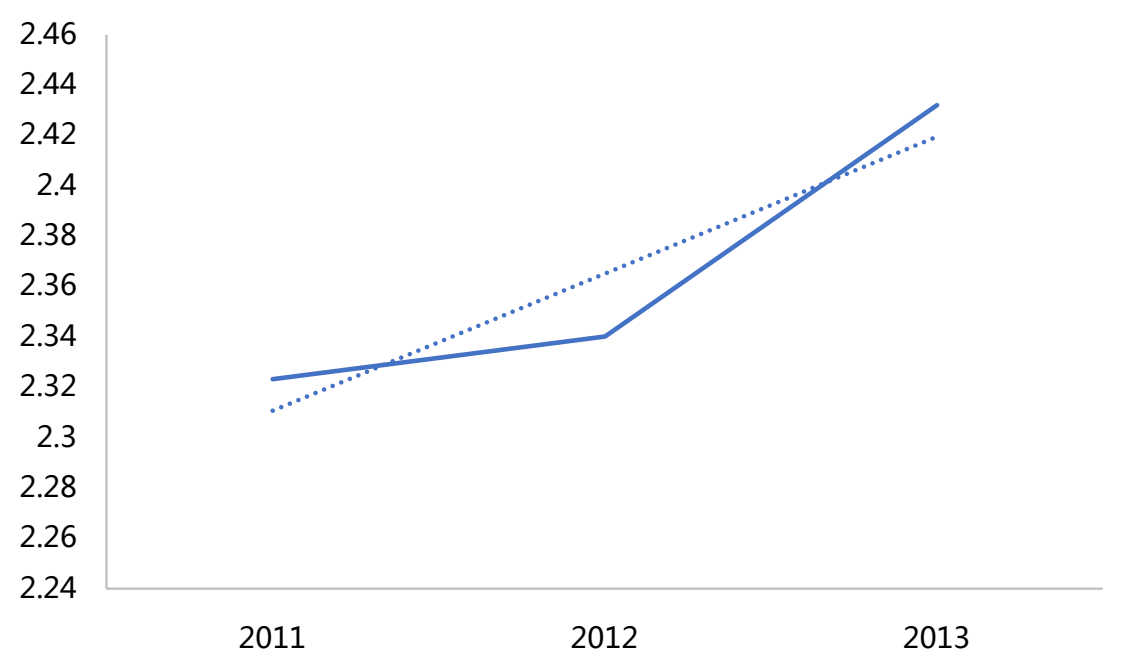

Figure 2. Annual rising trend on health risk of the 12 pesticide residues indicated that their HIT on adults.

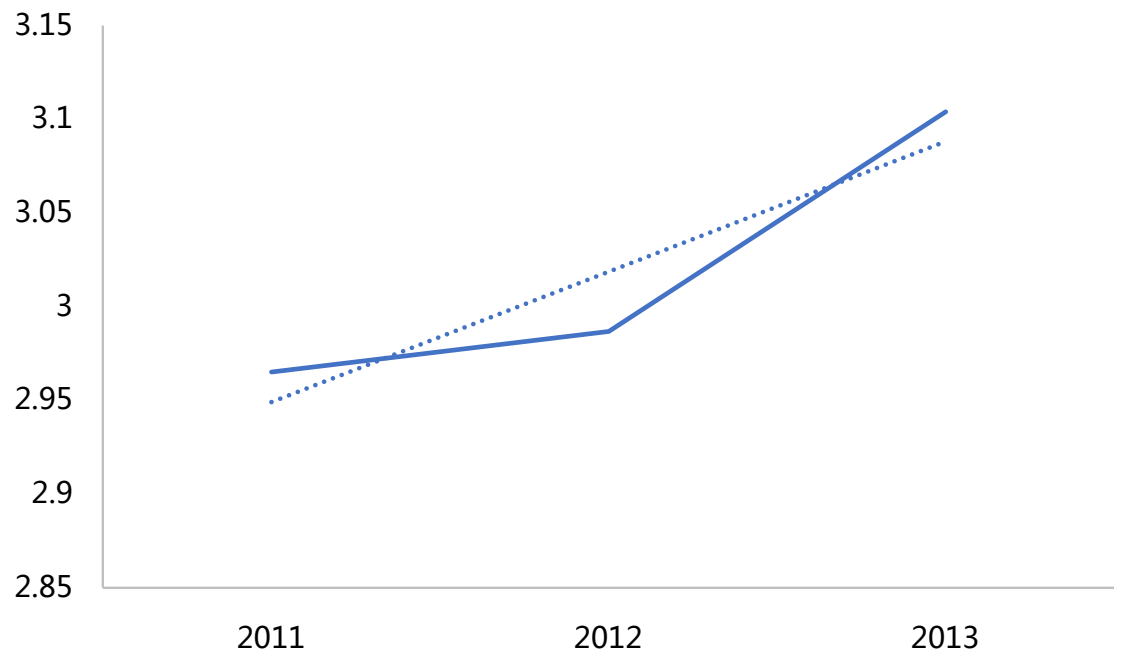

Figure 3. Annual rising trend on health risk of the 12 pesticide residues indicated that their HIT on children. 
that in the factory water (2.619 vs 2.366$)$, but lower HIT by the maximums values in pipe water comparing to that in factory water (5.240 vs 5.395$)$. Dimethoate was the main resource of in factory water $(\mathrm{HI}=2.003-3.991)$ and pipe water $(\mathrm{HI}=2.177$ - 3.991) on non-carcinogenic risk assessment. The total HIT from the median values of concentrations on the rest 11 pesticides except dimethoate was less than one $(\mathrm{HI}=0.363-0.442)$, but the total HIT greater than one by analysing their maximum values of concentrations of the 11 pesticides either in factory water or in pipe water ( $\mathrm{HI}=1.249$ - 1.403). Therefore, hexachlorobenzene and heptachlor ranked the second and third among the 12 pesticides on health risk (see Table 5).

\section{Discussion}

The study indicated that the maximum values of all the samples measured do not exceed the limit specified in Standards for Drinking Water Hygiene (GB 5749-2006), but the annual non-carcinogenic risks of adults and children on 12 pesticide residues such as heptachlor were greater than $1(2.323-6.312)$ by the US EPA recommended risk assessment model. Meanwhile, the approximate $80 \%$ of the risks came from dimethoate, of which the annual personal non-carcinogenic risks were greater than 1 (1.995 - 5.094) with a slow upward trend year by year, and which risks on children were higher than those on adults. The reasons of this could be related to the increase in the production and use of pesticides in China, and the dimethoate was the main pesticide of fruit trees and vegetables

Table 5. Non-carcinogenic risk assessment on the 12 pesticides in factory water, pipe water and secondary supply water in Shenzhen $\left(\times 10^{-3}\right)$.

\begin{tabular}{|c|c|c|c|c|c|c|}
\hline \multirow[t]{2}{*}{ Pesticides } & \multicolumn{2}{|c|}{$\begin{array}{c}\text { The risk of factory } \\
\text { water }\end{array}$} & \multicolumn{2}{|c|}{ The risk of pipe water } & \multicolumn{2}{|c|}{$\begin{array}{c}\text { The risk of secondary } \\
\text { supply water }\end{array}$} \\
\hline & Median & Maximum & Median & Maximum & Median & Maximum \\
\hline Heptachlor & 165.26 & 319.34 & 174.04 & 319.34 & 159.67 & \\
\hline Pentachlorophenol & 9.88 & 79.83 & 15.25 & 79.83 & 79.83 & \\
\hline Hexachlorocyclohexane & 56.50 & 133.06 & 67.01 & 133.06 & 66.53 & \\
\hline Hexachlorobenzene & 21.16 & 498.96 & 69.66 & 498.96 & 0.50 & \\
\hline DDT & 1.82 & 3.99 & 2.18 & 3.99 & 2.00 & \\
\hline Malathion & 24.47 & 199.59 & 21.77 & 39.92 & 19.96 & \\
\hline Glyphosate & 0.12 & 0.20 & 0.10 & 0.16 & 0.06 & \\
\hline Dimethoate & 2003.04 & 3991.71 & 2177.48 & 3991.71 & 1995.85 & \\
\hline Bentazone & 0.55 & 1.33 & 1.21 & 6.65 & 0.67 & \\
\hline Atrazine & 0.64 & 2.28 & 0.95 & 2.28 & 1.14 & \\
\hline Chlorothalonil & 2.69 & 5.32 & 2.90 & 5.32 & 2.66 & \\
\hline Carbofuran & 80.79 & 159.67 & 87.10 & 159.67 & 79.83 & \\
\hline Total & 2366.92 & 5395.27 & 2619.64 & 5240.89 & 2408.70 & \\
\hline Total except dimethoate & 363.88 & 1403.56 & 442.16 & 1249.18 & 412.85 & \\
\hline
\end{tabular}


in the south of China [11] [12] [13] [14]. The reason of mean risk values of pipe water being greater than that of factory water is related to the secondary chlorination in the water transportation and the pipe material and the long pipeline transportation [4] [10].

Crentsil et al. [3] reported the organochlorine pesticide residues and health risk assessment results of Accra Metropolis in Ghana, which indicated that residual levels of pesticides on self-produced papaya, tomatoes and imported apples were $<0.01$ to $0.11 \mu \mathrm{g} / \mathrm{g}$, and the risk values of heptachlor, epoxy heptachlor, endrin aldehyde and endrin ketone were greater than 1 , and the risk values of children were greater than those of adults.

Guohong Zhou et al. [15] reported that the non-carcinogenic health risk index of trihalomethane, a by-product of drinking water disinfection in Shenzhen, was less than 1, but its carcinogenic risk was close to the critical value, and the risk values of cancer in 3 factory waters exceeded the critical value. Our previous research on the health risk analysis of three kinds of toxic substances, such as arsenic and other toxic substances in drinking water in Shenzhen, indicated that the health risks of these 15 chemicals were still in control by the International Radiation Protection Committee, and the risk of carcinogens was greater than that of non-carcinogens, and the risk of children was higher than that of adults [16].

Of course, this study was referenced to the methods of pesticide residues in drinking water exposure to human health risk assessment in USEPA, and we only considered the exposure way of water intake average, and other exposure ways, such as food intake, swimming, bathing, and skin exposure pathway, were out of consideration. The reference dose selection, ethnicity, living habits, and the mechanism of various pesticides are different because of the lack of exposure parameter standards in China. Therefore, there may be some bias in the results of this evaluation [17] [18] [19]. The comprehensive study of environmental exposures to pesticides, including food and water intake, skin and respiratory exposures, is needed in the further.

\section{Acknowledgements}

We would like to thank to Department of Environment and Health of Shenzhen CDC for chemical dataset for this study. The authors thank the 10 district CDCs in Shenzhen for water samples collection. Also, we like to thank laboratory of Shenzhen CDC for their collaboration.

\section{Conflicts of Interest}

The authors declare no conflicts of interest regarding the publication of this paper.

\section{References}

[1] Renwick, A.G. (2002) Pesticide Residue Analysis and Its Relationship to Hazard 
Characterisation (ADI/ARfD) and Intake Estimations (NEDI/NESTI). Pest Management Science, 58, 1073-1082. https://doi.org/10.1002/ps.544

[2] Thompson, C.M., Gaylor, D.W., Tachovsky, J.A., Perry, C., Carakostas, M.C. and Haws, L.C. (2013) Development of a Chronic Noncancer Oral Reference Dose and Drinking Water Screening Level for Sulfolane Using Benchmark Dose Modeling. Journal of Applied Toxicology, 33, 1395-1406. https://doi.org/10.1002/jat.2799

[3] Sun, F., Wong, S.S., Li, G.C. and Chen, S.N. (2006) A Preliminary Assessment of Consumer's Exposure to Pesticide Residues in Fisheries Products. Chemosphere, 62, 674-680. https://doi.org/10.1016/j.chemosphere.2005.04.112

[4] Bempah, C.K., Donkor, A., Yeboah, P.O., Dubey, B. and Osei-Fosu, P. (2011) A Preliminary Assessment of Consumer's Exposure to Organochlorine Pesticides in Fruits and Vegetables and the Potential Health Risk in Accra Metropolis, Ghana. Food Chemistry, 128, 1058-1065. https://doi.org/10.1016/j.foodchem.2011.04.013

[5] Caylak, E. (2012) Health Risk Assessment for Trace Metals, Polycyclic Aromatic Hydrocarbons and Trihalomethanes in Drinking Water of Cankiri, Turkey. European Journal of Chemistry, 9, 1976-1991.

[6] Spickett, J., Katscherian, D. and Yang, M.G. (2012) A New Approach to Criteria for Health Risk Assessment. Environmental Impact Assessment Review, 32, 118-122. http://trove.nla.gov.au/work/158426291

[7] Fosu-Mensah, B.Y., Okoffo, E.D., Darko, G. and Gordon, C. (2016) Organophosphorus Pesticide Residues in Soils and Drinking Water Sources from Cocoa Producing Areas in Ghana. Environmental Systems Research, 5, 1-12. https://doi.org/10.1186/s40068-016-0063-4

[8] Approved by the Ministry of Health (2007) Standard Test Method for Drinking Water. GB 5750-2006, China Standard Press, 638-640.

[9] Ma, G.S. (2011) Current Status of Drinking Water for Adult Residents in Four Cities of China. In China Drinking Water Recommendations Workshop Compilation Manual.

[10] (2008) 2016 Guangdong National Fitness Monitoring Bulletin, Guangdong Provincial Sports Bureau. http://www.tyj.gd.gov.cn/4294332/5323796.html

[11] Moya, J. (2009) Exposure Factors Handbook 2009 Update (External Review Draft). https://cfpub.epa.gov/ncea/risk/recordisplay.cfm?deid=209866

[12] Pinheiro, M.C., Oikawa, T., Vieira, J.L., Gomes, M.S., Guimarães, G.A., Crespo-López, M.E., Müller, R.C., Amoras, W.W., Ribeiro, D.R., Rodrigues, A.R., Côrtes, M.I. and Silveira, L.C. (2006) Comparative Study of Human Exposure to Mercury in Riverside Communities in the Amazon Region. Brazilian Journal of Medical \& Biological Research, 39, 411-414.

[13] Biksey, T.M., Schultz, A.C., Bernhardt, A.M., Marion, B. and Peterson, C. (2004) Ecological and Human Health Risk Assessment. Water Environment Research, 76, 2510-2567. https://doi.org/10.2175/106143004X145894

[14] Hoque, Y.M., Tripathi, S., Hantush, M.M. and Govindaraju, R.S. (2012) Watershed Reliability, Resilience and Vulnerability Analysis under Uncertainty Using Water Quality Data. Journal of Environmental Management, 109, 101-112. https://doi.org/10.1016/j.jenvman.2012.05.010

[15] Zhou, G.H., Yu, S.Y., Peng, C.Q., Liu, G.H., Liu, N., Huang, G.W., Lan, T., Liu, G.H., Sun, Q.L. and Li, B. (2013) Health Risk Assessment of Trihalomethane as a By-Product of Disinfection in Drinking Water in Shenzhen City. Journal of Environment and Health, 30, 718-722. 
[16] Liu, G.H., Lan, T., Xu, X.Y., Huang, G.W., Li, J., Yu, S.Y., Ci, J.Y., Liu, G.H., Wang, W. and Wang, X.B. (2014) Shenzhen Municipal Water Supply Health Risk Assessment. Journal of Environmental Hygiene, 2014, 119-124.

[17] Kimmel, C.A. (2001) U.S. EPA Reference Dose/Reference Concentration Methodology: Update on a Review of the Process. Human \& Ecological Risk Assessment: An International Journal, 7, 117-123. https://doi.org/10.1080/20018091094231

[18] Ma, J. and Singhirunnusorn, W. (2012) Distribution and Health Risk Assessment of Heavy Metals in Surface Dusts of MahaSarakham Municipality. Procedia-Social and Behavioral Sciences, 50, 280-293. https://doi.org/10.1016/j.sbspro.2012.08.034

[19] Goldhaber, S.B. (2003) Trace Element Risk Assessment: Essentiality vs. Toxicity. Regulatory Toxicology \& Pharmacology, 38, 232-242.

https://doi.org/10.1016/S0273-2300(02)00020-X 